\title{
Orexin Signaling Mediates the Antidepressant-Like Effect of Calorie Restriction
}

\author{
Michael Lutter, Vaishnav Krishnan, Scott J. Russo, Saendy Jung, Colleen A. McClung, and Eric J. Nestler \\ Departments of Psychiatry and Neuroscience, The University of Texas Southwestern Medical Center, Dallas, Texas 75390-9070
}

During periods of reduced food availability, animals must respond with behavioral adaptations that promote survival. Despite the fact that many psychiatric syndromes include disordered eating patterns as a component of the illness, little is known about the neurobiology underlying behavioral changes induced by short-term calorie restriction. Presently, we demonstrate that $10 \mathrm{~d}$ of calorie restriction, corresponding to a $20-25 \%$ weight loss, causes a marked antidepressant-like response in two rodent models of depression and that this response is dependent on the hypothalamic neuropeptide orexin (hypocretin). Wild-type mice, but not mice lacking orexin, show longer latency to immobility and less total immobility in the forced swim test after calorie restriction. In the social defeat model of chronic stress, calorie restriction reverses the behavioral deficits seen in wild-type mice but not in orexin knock-out mice. Additionally, chronic social defeat stress induces a prolonged reduction in the expression of prepro-orexin mRNA via epigenetic modification of the orexin gene promoter, whereas calorie restriction enhances the activation of orexin cells after social defeat. Together, these data indicate that orexin plays an essential role in mediating reduced depression-like symptoms induced by calorie restriction.

Key words: orexin; hypocretin; stress; calorie restriction; antidepressant; hypothalamus

\section{Introduction}

Calorie restriction and subsequent weight loss in mammals induces a wide array of behavioral responses directed toward promoting the identification of new food sources. These responses have been well studied in mice and include increased arousal, increased locomotor activity, and decreased anxiety-like behavior (Marchant and Mistlberger, 1997; Yamanaka et al., 2003; Inoue et al., 2004). Interestingly, several psychiatric disorders, notably "typical" major depressive disorder and anorexia nervosa, are characterized by reduced calorie intake. Behavioral responses to calorie restriction are thought to mediate certain clinical aspects of the illness. For example, reduced production of leptin by adipose tissue has been implicated in the increased psychomotor activity of patients suffering from anorexia nervosa (Holtkamp et al., 2003).

Although the neurochemical consequences of chronic calorie restriction have been well studied (Jahng et al., 2007; Martin et al., 2007), the underlying neurobiological mechanism of short-term calorie restriction is less clear. The hypothalamic neuropeptide orexin (hypocretin) offers an attractive candidate for understanding the behavioral effects of calorie restriction. The activity of orexin neurons is regulated by energy balance (Yamanaka et al., 2003), and orexin neurons mediate certain complex behaviors

Received Aug. 26, 2007; revised Jan. 17, 2008; accepted Feb. 3, 2008.

This work was supported by grants from the National Institute of Mental Health. We thank Joel Elmquist, Jeffrey Zigman, Michael Scott, Masashi Yanagisawa, and Jon Willie for helpful discussions. We also thank Michelle Mazei, Jessica Ables, Quincey Laplant, Shari Birnbaum, Ami Grahm, and Cathy Steffen for technical assistance.

Correspondence should be addressed to Michael Lutter, Departments of Psychiatry and Neuroscience, The University of Texas Southwestern Medical Center, 5323 Harry Hines Boulevard, Dallas, TX 75390-9070. E-mail: michael.lutter@utsouthwestern.edu.

DOI:10.1523/JNEUROSCI.5584-07.2008

Copyright $\odot 2008$ Society for Neuroscience $\quad$ 0270-6474/08/283071-05\$15.00/0 such as the increase in locomotor activity observed during periods of reduced calorie availability and after withdrawal from morphine (Georgescu et al., 2003; Yamanaka et al., 2003; Mieda et al., 2004). Furthermore, orexin signaling has been implicated in the regulation of food and drug reward, indicating a role for orexin signaling in emotional processes (Harris et al., 2005). The aim of the current study was to characterize the effects of calorie restriction in rodent models of depression-like behavior and to elucidate the neurobiological basis of calorie restriction-induced behavioral changes by exploring a role for orexin.

\section{Materials and Methods}

Animals and housing. Mice were single housed and maintained on a $12 \mathrm{~h}$ light/dark cycle with access to food and water ad libitum unless noted otherwise. All animal procedures were performed in accordance with Institutional Animal Care and Use Committee guidelines. Adult C57BL/6 mice (8-10 weeks old; The Jackson Laboratory, Bar Harbor, $\mathrm{ME})$ were used as noted for behavioral testing. Orexin-deficient mice were generated as reported previously (Chemelli et al., 1999) and have been backcrossed 10 generations onto C57BL/6. Breeding of mice was performed in house with all behavioral testing performed on null mice and their wild-type littermates.

Calorie restriction. After $3 \mathrm{~d}$ of individual housing, mice were given a food pellet equal to $60 \%$ of their average daily food intake before onset of the dark phase (7:00 P.M.) when the animals normally awake and take their first large meal of the evening.

Locomotor activity. Individually housed animals were kept in their home cage, and locomotor activity was measured for the indicated times by photocell beams linked to computer data acquisition software (San Diego Instruments, San Diego, CA).

Forced swim test. The forced swim test was performed according to published protocols (Krishnan et al., 2007). Mice were videotaped while in a $4 \mathrm{~L}$ Pyrex glass beaker containing $3 \mathrm{~L}$ of water at $24 \pm 1^{\circ} \mathrm{C}$ for $6 \mathrm{~min}$. The videotape was scored manually by two trained and blinded observ- 
ers. After a 2 min lead time, latency to immobility (latency) was determined as the first cessation of all movement for $3 \mathrm{~s}$. Total immobility was measured as the time spent without any motion except for single limb paddling to maintain flotation.

Chronic social stress. Defeat stress is performed using a method reported recently (Berton et al., 2006). C57BL/6 test mice were exposed to a different CD1 aggressor mouse each day for 10 min over a total of $10 \mathrm{~d}$. During the brief exposure, all defeated mice showed signs of stress and subordination, including vocalization, flight response, and submissive posture. After the 10 min of physical contact, test mice were separated from the aggressor and placed across a plastic separator with holes, in which they remained in sensory contact with the CD1 aggressor for the remainder of the $24 \mathrm{~h}$. Control test mice were housed in equivalent cages but with members of the same strain and were handled gently by placing the animal in the palm of the hand every day for $30 \mathrm{~s}$. Mice were individually housed $24 \mathrm{~h}$ the last session. We used a social interaction task starting at 10:00 A.M. to measure the behavioral consequences of the chronic defeat stress. Mice were placed in an arena with a small animal cage at one end, with their movement tracked for $2.5 \mathrm{~min}$ in the absence of a mouse, followed by $2.5 \mathrm{~min}$ in the presence of a caged unfamiliar mouse. The duration in the interaction zone and other measures were obtained using Ethovision 3.0 software (Noldus, Leesburg, VA).

Chromatin immunoprecipitation. Chromatin immunoprecipitation (ChIP) was performed as reported recently (Tsankova et al., 2006) using a commercially available ChIP kit (catalog \#17-295; Millipore, Billerica, MA) with anti-dimethyl lysine $9 \mathrm{H} 3$ antisera (Millipore). Relative amount of orexin promoter was determined by quantitative real-time PCR expressed as fold increase of antibody over IgG control ( $n=4$ pools of 2 hypothalami/group). Student's $t$ test reports a significant effect of social defeat (control, $1.0 \pm 0.62$ vs social defeat, $3.7 \pm 0.44 ; p=0.0032$ ).

Quantitative PCR analysis. Mice were killed by cervical dislocation, the brains were rapidly removed, the hypothalamus was grossly dissected, and samples were immediately placed on dry ice and stored at $-80^{\circ}$ until processing. High-quality mRNA was isolated by Trizol (Invitrogen, Carlsbad, CA) and chloroform (Sigma, St. Louis, MO) extraction and column purification following the directions of the kit (catalog \#74004; Qiagen, Valencia, CA). Complementary DNA was synthesized from 500 ng of mRNA by random hexamer priming (catalog \#12371-019; Invitrogen). Twenty nanograms of cDNA were amplified in triplicate using $8 \mathrm{pg}$ of the stated primer with quantification of the DNA product by SYBR Green binding (catalog \#4367659; Applied Biosystems, Foster City, CA). All genes were standardized to cyclophilin, and gene expression was determined for all mRNA data by fold change relative to control using the $\Delta \Delta \mathrm{Ct}$ method as reported previously (Tsankova et al., 2006).

Primers. Sequences for primers were reported previously (de Rijke et al., 2005) except for orexin promoter: cyclophilin $\left(60^{\circ}\right)$, GCCTGTGGAATGTGAGGGGTG CATCTATGGTGAGCGCTTCCCA; orexin $\left(60^{\circ}\right)$, GCCGTCTCTACGAACTGTTG CGAGGAGAGGGGAAGTTAG; orexin promoter $\left(60^{\circ}\right)$, GGAGTTTGGTGAAAGGGACAG CTGGGTGGCATACCCTCTCA.

Dual-label immunohistochemistry. Eight-week-old C57BL/6 mice received $10 \mathrm{~d}$ of chronic social defeat stress followed by $10 \mathrm{~d}$ of calorie restriction or ad libitum feeding as described above. On the following day, the mice were tested for social interaction. One hour after the social interaction test, mice were anesthetized and perfused transcardially with cold $4 \%$ paraformaldehyde in PBS, $\mathrm{pH}$ 7.4. Brains were postfixed in $4 \%$ paraformaldehyde overnight and stored in $30 \%$ sucrose in PBS. Thirty micrometer sections were collected on a freezing microtome in the coronal plane. Sections were stored in PBS supplemented with $0.01 \%$ sodium azide.

Immunohistochemistry was performed on free-floating sections using the following primary antibodies: rabbit anti-c-Fos antisera (PC38; Calbiochem, San Diego, CA) and goat anti-orexin antisera (SC-8070; Santa Cruz Biotechnology, Santa Cruz, CA). Primary antibodies were incubated overnight in 3\% normal donkey serum and $0.3 \%$ Tween 20 in PBS at 1:100 (orexin) and 1:10,000 (c-Fos) dilutions. This was followed by incubation for $2 \mathrm{~h}$ with the following fluorescent-tagged secondary antibodies: cyanine-3-conjugated donkey anti-goat IgG and cyanine-5conjugated donkey anti-rabbit IgG (Jackson ImmunoResearch, West
Grove, PA), both at a 1:200 dilution. Sections were mounted on Superfrost Plus slides (Fischer Scientific, Pittsburg, PA), dehydrated, and coverslipped.

Microscopic quantification. Cells were visualized by using a confocal microscope LSM510-META (Zeiss, Thornwood, NY), with emission wavelengths of 543 and 633 and magnification of $20 \times$. Scanning and optical sectioning in the $Z$-plane was performed as described previously (Russo et al., 2007). For counting orexin-positive cells, two bilateral images were collected and three contiguous boxes $0.2 \times 0.2 \mathrm{~mm}$ were drawn in the region of the lateral hypothalamus with the highest concentration of orexin-positive cells (approximately bregma $-1.8 \mathrm{~mm}$ ) using Zeiss LSM Image Browser (version 4.0.0.421). Individual cells were visualized in the $Z$-plane, counted, and summed together for the total number of cells in a $0.12 \mathrm{~mm}^{2}$ area.

For c-Fos colocalization, 50 orexin cells in the lateral hypothalamus were counted for each animal. Verification of colabeling of orexin and c-Fos staining was achieved by visualizing stacks of images in the $Z$-plane using Zeiss LSM Image Browser to confirm colocalization. Representative fluorescently labeled confocal images from a single optical slice were imported into Photoshop (Adobe Systems, San Jose, CA) for presentation. Total number of c-Fos/orexin double-labeled cells used for Figure $2 D$ was estimated by multiplying percentage c-Fos/orexin colabeled cells by the concentration of orexin-positive cells.

Statistical analyses. The data are reported as mean \pm SEM. Statistical analyses were performed using a two-way ANOVA, followed by a Bonferroni's post hoc test. All statistical analyses were performed using Prism (version 4.0) software. Statistical significance was defined as $p<0.05$.

\section{Results}

Wild-type and orexin null mice were given $60 \%$ of ad libitum calories for $10 \mathrm{~d}$ as reported in Materials and Methods. This feeding schedule resulted in a significant weight loss in both genotypes for male and female mice compared with control mice with ad libitum access to food (supplemental Figs. $A, B$, available at www.jneurosci.org as supplemental material). Because feeding of a calorie-restricted diet can alter an animal's activity pattern, the mice were tested for locomotor activity in their home cage. We found that calorie restriction caused an increase in locomotor activity just before the dark phase (supplemental Fig. $C$, available at www.jneurosci.org as supplemental material), which is similar to the food-anticipatory activity published previously (Mieda et al., 2004). As reported, this food-anticipatory activity was blunted in orexin knock-out mice. To account for this difference in activity level, all subsequent behavioral testing was performed between 10:00 A.M. and 12:00 P.M. when both ad libitum-fed and calorie-restricted mice displayed equivalent locomotor activity.

As a first test of depression-like behavior, we analyzed the effect of calorie restriction in the forced swim test. As shown in Figure 1, $A$ and $B$, we found a dramatic antidepressant-like effect of calorie restriction in male and female wild-type mice, as indicated by an increased latency to immobility and a reduction in total immobility. In striking contrast, both male and female mice deficient in orexin do not show a calorie restriction-induced improvement in the forced swim test. Importantly, mice fasted overnight only do not show an antidepressant-like effect in the forced swim test (supplemental Fig. D, available at www. jneurosci.org as supplemental material), indicating the importance of neuroplastic adaptations to sustained calorie restriction, and not just simple hunger, in the behavioral differences observed.

Because antidepressant medications induce a change in the forced swim test after a single dose, unlike the clinical treatment of human major depression in which antidepressant medications require several weeks to work, we were interested in studying the role of calorie restriction in a complementary measure of 
A

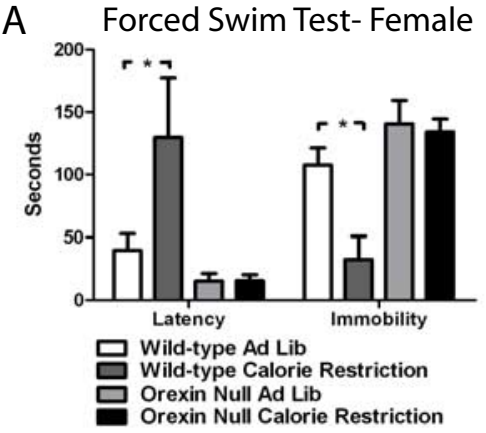

C Social Interaction Test

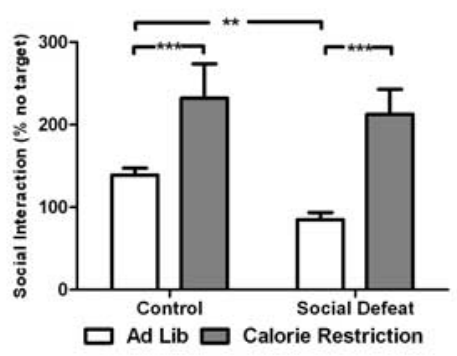

B Forced Swim Test- Male

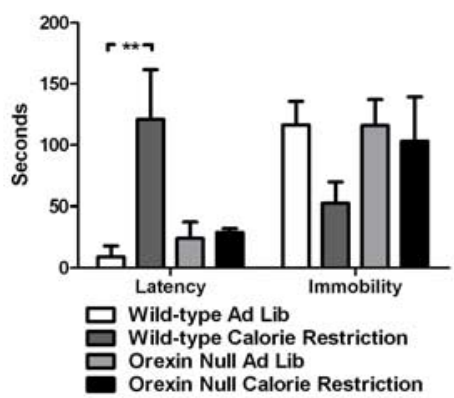

D Social Interaction Test

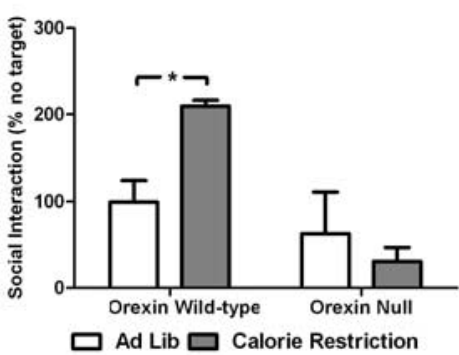

Figure 1. Orexin signaling mediates the antidepressant-like effect of acute calorie restriction. $\boldsymbol{A}$, Forced swim test results for female orexin null mice and wild-type littermates fed ad libitum ( $n=6$ wild-type and 10 null) or calorie restricted $(n=5$ wild-type and 6 null). For latency, two-way ANOVA reports a significant interaction $\left(F_{(1.23)}=5.31, p=0.03\right)$ and significant effects for genotype $\left(F_{(1,23)}=12.63, p=0.002\right)$ and for diet $\left(F_{(1,23)}=5.35, p=0.03\right)$. For immobility, two-way ANOVA reports a nonsignificant interaction $\left(F_{(1,23)}=3.58, p=0.07\right)$ with significant effects for genotype $\left(F_{(1,23)}=13.90, p=0.001\right)$ and for $\operatorname{diet}\left(F_{(1,23)}=5.10, p=0.03\right)$. Bonferroni's post hoc test analysis demonstrated a significant effect for latency and immobility $\left({ }^{*} p<0.05\right)$ only in wild-type mice. $\boldsymbol{B}$, Forced swim test results for male orexin null mice and wild-type littermates fed ad libitum ( $n=5$ wild-type and 7 null) or calorie restricted ( $n=5$ wild-type and 5 null). For latency, two-way ANOVA reports a significant interaction $\left(F_{(1,18)}=6.59, p=0.02\right)$ and nonsignificant effect for genotype $\left(F_{(1,18)}=3.37, p=0.08\right)$ but a significant effect for $\operatorname{diet}\left(F_{(1,18)}=7.80, p=0.01\right)$. For immobility, two-way ANOVA reports a nonsignificant interaction $\left(F_{(1,18)}=1.07, p=0.32\right)$ and nonsignificant effects for genotype $\left(F_{(1,18)}=1.02, p=0.33\right)$ and for diet $\left(F_{(1,18)}=2.41, p=0.14\right)$. Bonferroni's posthoc test analysis demonstrated a significant effectfor latency $\left({ }^{*} p<0.05\right.$ ) only in wild-type mice. Eight-week-old C57BL/6 male mice were individually housed and subjected to either social defeat daily for $10 \mathrm{~d}$ or daily handling (Control). After the social defeat paradigm, mice received either ad libitum feeding or calorie restriction for $10 \mathrm{~d}$. On the following day (day 21 overall), social interaction was measured by comparing time spent interacting with an unfamiliar mouse with an empty target. $\boldsymbol{C}$, Interaction time presented as a percentage of target absent ( $n=28$ per group for ad libitum and 9 per group for calorie restriction). Two-way ANOVA showed a main effect for diet $\left(F_{(1,70)}=38.97, p<0.0001\right)$ and for social defeat $\left(F_{(1,70)}=4.34, p=0.04\right)$ with no interaction $\left(F_{(1,70)}=\right.$ $0.95, p=0.33)$. Bonferroni's post hoc test analysis demonstrated a significant effect for calorie restriction in both groups $\left({ }^{* * *} p<\right.$ 0.001). Planned a posteriori analysis demonstrated that social defeat causes a significant decrease in social interaction in ad libitum-fed animals $\left({ }^{* *} p<0.01\right)$. $\boldsymbol{D}$, Calorie restriction increases time spent in the interaction zone in wild-type mice, but not orexin null mice, after social defeat ( $n=5$ per group). Two-way ANOVA demonstrates a significant effect for genotype $\left(F_{(1,16)}=\right.$ $14.54, p=0.002)$, no effect for diet $\left(F_{(1,16)}=1.90, p=0.19\right)$, and a significant interaction $\left(F_{(1,16)}=6.35, p=0.02\right)$. Bonferroni's post hoc test analysis demonstrated a significant effect for calorie restriction in wild-type mice only $\left({ }^{*} p<0.05\right)$. All error bars presented as SEM.

depression-like behavior in rodents. Chronic social defeat stress is an established model of stress-induced depression-like behavior in male mice (Berton et al., 2006). Unlike the forced swim test, chronic, but not acute, administration of antidepressant medication reverses the long-lasting stress-induced decrease in social interaction. After the $10 \mathrm{~d}$ course of social defeat stress, defeated and control male mice were individually housed and fed either ad libitum or calorie restricted for an additional $10 \mathrm{~d}$. We found that calorie restriction increased social interaction in control mice. Moreover, we found that calorie restriction not only completely reversed social interaction deficits induced by social defeat, it also increased social interaction scores to the elevated levels seen in control calorie-restricted animals (Fig. 1C). To confirm the involvement of orexin in these calorie restriction-induced behavioral changes, we tested orexin null mice and their wild-type littermate controls in the social defeat paradigm. After chronic social defeat, wildtype animals, but not orexin null mice, responded to calorie restriction with increased social interaction (Fig. 1D). Importantly, no improvement in social interaction was observed in control orexin null mice that were calorie restricted but not subjected to social defeat stress (127.7 \pm 37.5 vs $116.2 \pm 53.1 \%, n=6$ per group, $p<0.05$ ), indicating that orexin signaling increases social interaction time regardless of whether an animal has been stressed.

Having established that calorie restriction induces an orexin-dependent antidepressant-like effect in two mouse models of depression, we next sought to determine whether chronic stress disrupts orexin signaling. After social interaction testing, the mice from Figure $1 C$ were killed, and prepro-orexin mRNA in the hypothalamus was measured by quantitative PCR. We found that mice subjected to chronic social defeat stress have an almost twofold decrease in prepro-orexin mRNA levels compared with control mice (Fig. $2 A)$. Furthermore, the calorie restrictioninduced improvement in social interaction after chronic social defeat stress is not a result of increased expression of preproorexin mRNA because no difference in expression was detected. To determine the mechanism by which chronic social defeat stress downregulates prepro-orexin mRNA expression, we preformed ChIP experiments to assess functional alterations on histones at the orexin gene promoter. After chronic social defeat stress, there is a 3.7-fold increase in the amount of the dimethyl modification on lysine 9 of histone 3 at the orexin promoter (1.0 \pm 0.62 vs $3.7 \pm 0.44, p=0.0032$ ), a modification previously associated with gene repression (Tsankova et al., 2006).

Because calorie restriction did not effect expression of prepro-orexin mRNA, we hypothesized that calorie restriction might instead enhance activation of orexin neurons during behavioral testing. To directly test this possibility, wild-type mice were subjected to $10 \mathrm{~d}$ of chronic social defeat stress, followed by $10 \mathrm{~d}$ of calorie restriction. Mice were then tested for social interaction and perfused $1 \mathrm{~h}$ later. Tissue sections were collected and double labeled with antisera against orexin and c-Fos, a marker of neuronal activation. Consistent with our mRNA findings, social defeat reduces the number of orexinpositive neurons in the lateral hypothalamic area (Fig. $2 \mathrm{~B}$ ). However, calorie restriction induced a significant increase in the percentage of orexin neurons that are activated during the social interaction test (as measured by c-Fos expression) in both control and social defeat groups. (Fig. $2 C, E$ ). In fact, regression analysis revealed a strong correlation $\left(R^{2}=0.6440\right)$ between the number of orexin cells expressing c-Fos and the degree of social defeat (i.e., social interaction scores) (Fig. 2D). 


\section{Discussion}

The current data support a novel role for orexin signaling in the antidepressant-like effect of calorie restriction. Our findings demonstrate significant downregulation of prepro-orexin mRNA expression after chronic social defeat stress. Interestingly, decreased levels of orexin-A were reported recently in the CSF of suicidal patients with major depressive disorder (Brundin et al., 2007), supporting chronic social defeat stress as a model of major depression. One interesting possibility is that prolonged reduction in orexin signaling may contribute to the development of neurovegetative symptoms seen in major depression. Orexin neurons have broad projections, and multiple functions have been attributed to orexin signaling, including consolidation of arousal, regulation of metabolism, food intake, and cardiovascular responses, controlling fluid intake, and mediating food and drug reward responses (Estabrooke et al., 2001; Harris et al., 2005, 2007; Samson et al., 2005; Harris and Aston-Jones, 2006). Given the multiple roles of orexin neurons, reduction in orexin signaling makes an attractive candidate to explain the disrupted sleep/wake cycles, altered appetite, and psychomotor retardation often observed in depressed patients.

However, diminished orexin signaling alone is unlikely to generate the full spectrum of symptoms observed in depression. Ad libitum-fed orexin knock-out mice and their wild-type littermates exhibit similar behaviors in the forced swim test (Fig. 1A). Furthermore, control orexin mice display similar social interaction ratios to wildtype mice (127.7 vs $139.1 \%$ ), indicating that absence of orexin alone cannot reproduce the entire syndrome. Rather, we favor a model in which orexin may serve to integrate many of the behavioral responses to acute and chronic stress. Orexin neurons are activated not only by metabolic cues but also by numerous types of stress, including restraint, foot shock, and social stress (Yamanaka et al., 2003; Georgescu et al., 2005). Although orexin signaling may allow an animal to adapt to acute stressors, repeated activation of the orexin system may downregulate expression of prepro-orexin mRNA in the lateral hypothalamus, which may then decrease the ability to compensate to the effects of chronic stress. Calorie restriction, by increasing the activity of orexin neurons, would then reduce this vulnerability and induce antidepressant-like responses.

Orexin signaling could potentially alter
A

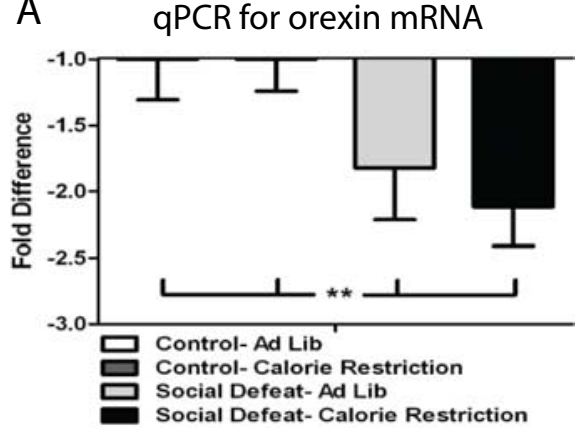

B

Orexin Cell Count

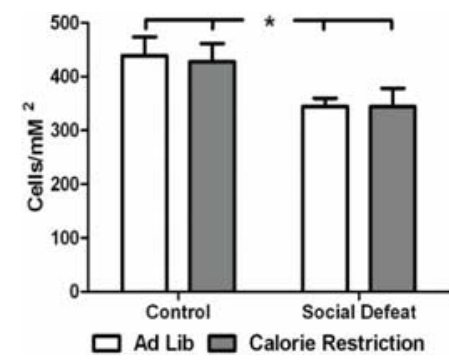

C c-Fos Positive Orexin Cells

D c-Fos Activation vs. Social Interaction
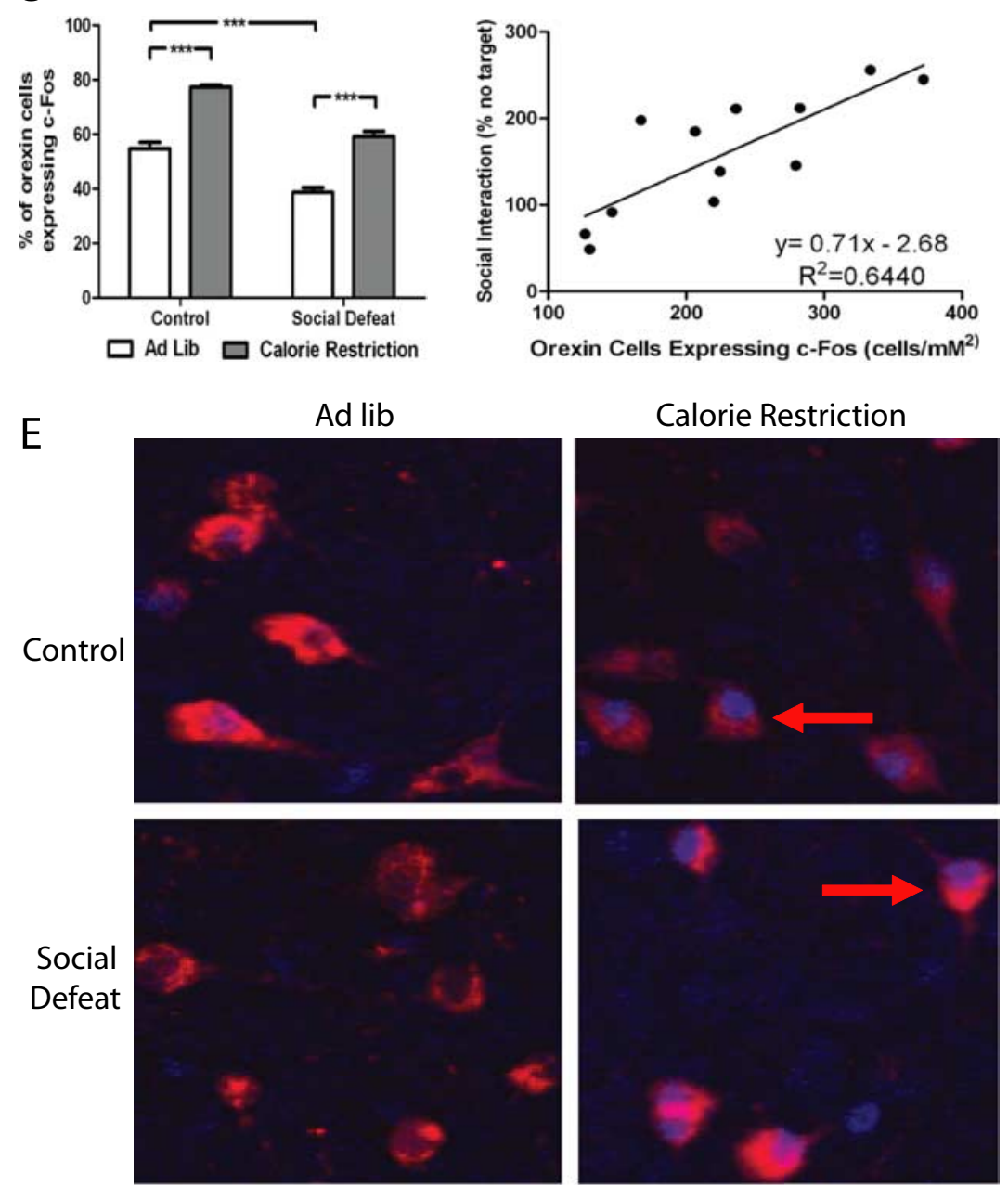

Figure 2. Orexin-dependent reversal of the effects of social defeat by calorie restriction. $A$, Mice from Figure $1 C$ were killed $1 \mathrm{~d}$ after testing social interaction, and prepro-orexin mRNA levels were determined by quantitative PCR ( $n=7$ per group). Two-way ANOVA reports a main effect for social defeat $\left(F_{(1,24)}=9.6, p=0.005\right)$ but no effect for diet $\left(F_{(1,24)}=0.22, p=0.64\right)$ or interaction $\left(F_{(1,24)}=0.22, p=0.64\right)$. Bonferroni's post hoc test analysis demonstrated no effect for calorie restriction in either group. Mice were subjected to social defeat and calorie restriction as in Figure $1 C$. On day 21, mice were tested for social interaction and then perfused with paraformaldehyde $1 \mathrm{~h}$ later. Tissue sections were processed for immunohistochemistry for orexin and $c-$ Fos. ( ${ }^{* *} p<0.01$.) $\boldsymbol{B}$, Concentration of orexin-positive neurons in the lateral hypothalamus at bregma $-1.8 \mathrm{~mm}$. Two-way ANOVA reports a main effect for social defeat $\left(F_{(1,8)}=8.46,{ }^{*} p=0.02\right)$ but no effect for diet $\left(F_{(1,8)}=0.03, p=0.86\right)$ or interaction $\left(F_{(1,8)}=0.03, p=0.86\right)$. Bonferroni's post hoc test analysis demonstrated no effect for calorie restriction in either group $(p>0.05)$. C, Percent of orexin-positive cells expressing c-Fos. Two-way ANOVA reports a main effect for social defeat $\left(F_{(1,8)}=92.89, p<0.0001\right)$ and for calorie restriction $\left(F_{(1,8)}=150.89, p<0.0001\right)$ with no significant interaction $\left(F_{(1,8)}=0.32\right.$, $p=0.57)$. Bonferroni's post hoc test analysis demonstrated a significant effect for calorie restriction in both groups $\left(^{* * *} p<\right.$ $0.001)$. Planned a posteriori analysis demonstrated that social defeat causes a significant decrease in the percentage of orexin cells expressing c-Fos $\left(^{* * *} p<0.001\right)$. D, Number of orexin cells expressing c-Fos plotted against social interaction scores. Best fit line calculated by linear regression $\left(R^{2}=0.6440\right)$. $E$, Representative photomicrographs of double-labeled orexin (red) and $c$-Fos (blue). Examples of double-labeled cells marked with red arrows. All error bars presented as SEM. 
depression-like behaviors at a number of sites associated with affective regulation, including the hippocampus, prefrontal cortex, ventral tegmental area, locus ceruleus, and dorsal raphe (orexin receptor 1) and nucleus accumbens and ventral tegmental area (orexin receptor 2) (Marcus et al., 2001). The ventral tegmental area and nucleus accumbens are particularly interesting sites given recent work that demonstrates its central role in mediating the reward deficits seen after social defeat (Berton et al., 2006; Krishnan et al., 2007).

The novel role for orexin signaling in antidepressant-like responses defined in the present study raises the interesting possibilities that orexin signaling may be involved in the mechanism of action of currently available antidepressant medications and that orexin receptor agonists, currently in development for the treatment of narcolepsy, may also have antidepressant-like activity.

\section{References}

Berton O, McClung CA, Dileone RJ, Krishnan V, Renthal W, Russo SJ, Graham D, Tsankova NM, Bolanos CA, Rios M, Monteggia LM, Self DW, Nestler EJ (2006) Essential role of BDNF in the mesolimbic dopamine pathway in social defeat stress. Science 311:864-868.

Brundin L, Bjorkqvist M, Petersen A, Traskman-Bendz L (2007) Reduced orexin levels in the cerebrospinal fluid of suicidal patients with major depressive disorder. Eur Neuropsychopharmacol 17:573-579.

Chemelli RM, Willie JT, Sinton CM, Elmquist JK, Scammell T, Lee C, Richardson JA, Williams SC, Xiong Y, Kisanuki Y, Fitch TE, Nakazato M, Hammer RE, Saper CB, Yanagisawa M (1999) Narcolepsy in orexin knockout mice: molecular genetics of sleep regulation. Cell 98:437-451.

de Rijke CE, Hillebrand JJ, Verhagen LA, Roeling TA, Adan RA (2005) Hypothalamic neuropeptide expression following chronic food restriction in sedentary and wheel-running rats. J Mol Endocrinol 35:381-390.

Estabrooke IV, McCarthy MT, Ko E, Chou TC, Chemelli RM, Yanagisawa M, Saper CB, Scammell TE (2001) Fos expression in orexin neurons varies with behavioral state. J Neurosci 21:1656-1662.

Georgescu D, Zachariou V, Barrot M, Mieda M, Willie JT, Eisch AJ, Yanagisawa M, Nestler EJ, DiLeone RJ (2003) Involvement of the lateral hypothalamic peptide orexin in morphine dependence and withdrawal. J Neurosci 23:3106-3111.

Georgescu D, Sears RM, Hommel JD, Barrot M, Bolanos CA, Marsh DJ, Bednarek MA, Bibb JA, Maratos-Flier E, Nestler EJ, DiLeone RJ (2005) The hypothalamic neuropeptide melanin-concentrating hormone acts in the nucleus accumbens to modulate feeding behavior and forced-swim performance. J Neurosci 25:2933-2940.

Harris GC, Aston-Jones G (2006) Arousal and reward: a dichotomy in orexin function. Trends Neurosci 29:571-577.

Harris GC, Wimmer M, Aston-Jones G (2005) A role for lateral hypothalamic orexin neurons in reward seeking. Nature 437:556-559.

Harris GC, Wimmer M, Randall-Thompson JF, Aston-Jones G (2007) Lat- eral hypothalamic orexin neurons are critically involved in learning to associate an environment with morphine reward. Behav Brain Res 183:43-51.

Holtkamp K, Herpertz-Dahlmann B, Mika C, Heer M, Heussen N, Fichter M, Herpertz S, Senf W, Blum WF, Schweiger U, Warnke A, Ballauff A, Remschmidt H, Hebebrand J (2003) Elevated physical activity and low leptin levels co-occur in patients with anorexia nervosa. J Clin Endocrinol Metab 88:5169-5174.

Inoue K, Zorrilla EP, Tabarin A, Valdez GR, Iwasaki S, Kiriike N, Koob GF (2004) Reduction of anxiety after restricted feeding in the rat: implication for eating disorders. Biol Psychiatry 55:1075-1081.

Jahng JW, Kim JG, Kim HJ, Kim BT, Kang DW, Lee JH (2007) Chronic food restriction in young rats results in depression- and anxiety-like behaviors with decreased expression of serotonin reuptake transporter. Brain Res 1150:100-107.

Krishnan V, Han MH, Graham DL, Berton O, Renthal W, Russo SJ, Laplant Q, Graham A, Lutter M, Lagace DC, Ghose S, Reister R, Tannous P, Green TA, Neve RL, Chakravarty S, Kumar A, Eisch AJ, Self DW, Lee FS, et al. (2007) Molecular adaptations underlying susceptibility and resistance to social defeat in brain reward regions. Cell 131:391-404.

Marchant EG, Mistlberger RE (1997) Anticipation and entrainment to feeding time in intact and SCN-ablated C57BL/6j mice. Brain Res 765:273-282.

Marcus JN, Aschkenasi CJ, Lee CE, Chemelli RM, Saper CB, Yanagisawa M, Elmquist JK (2001) Differential expression of orexin receptors 1 and 2 in the rat brain. J Comp Neurol 435:6-25.

Martin B, Pearson M, Kebejian L, Golden E, Keselman A, Bender M, Carlson O, Egan J, Ladenheim B, Cadet JL, Becker KG, Wood W, Duffy K, Vinayakumar P, Maudsley S, Mattson MP (2007) Sex-dependent metabolic, neuroendocrine, and cognitive responses to dietary energy restriction and excess. Endocrinology 148:4318-4333.

Mieda M, Williams SC, Sinton CM, Richardson JA, Sakurai T, Yanagisawa M (2004) Orexin neurons function in an efferent pathway of a foodentrainable circadian oscillator in eliciting food-anticipatory activity and wakefulness. J Neurosci 24:10493-10501.

Russo SJ, Bolanos CA, Theobald DE, DeCarolis NA, Renthal W, Kumar A, Winstanley CA, Renthal NE, Wiley MD, Self DW, Russell DS, Neve RL, Eisch AJ, Nestler EJ (2007) IRS2-Akt pathway in midbrain dopamine neurons regulates behavioral and cellular responses to opiates. Nat Neurosci 10:93-99.

Samson WK, Taylor MM, Ferguson AV (2005) Non-sleep effects of hypocretin/orexin. Sleep Med Rev 9:243-252.

Tsankova NM, Berton O, Renthal W, Kumar A, Neve RL, Nestler EJ (2006) Sustained hippocampal chromatin regulation in a mouse model of depression and antidepressant action. Nat Neurosci 9:519-525.

Yamanaka A, Beuckmann CT, Willie JT, Hara J, Tsujino N, Mieda M, Tominaga M, Yagami K, Sugiyama F, Goto K, Yanagisawa M, Sakurai T (2003) Hypothalamic orexin neurons regulate arousal according to energy balance in mice. Neuron 38:701-713. 